\title{
Acoustic Design and Repetitive Speech and Motor Movement in Children with Autism
}

\author{
Shireen Kanakri \\ Department of Family and Consumer Science, College of Applied Technology, Ball State University, USA
}

Copyright $\mathrm{C} 2017$ by authors, all rights reserved. Authors agree that this article remains permanently open access under the terms of the Creative Commons Attribution License 4.0 International License

\begin{abstract}
Emerging research in Evidence-Based Design for interiors such as classrooms has begun considering the unique sensory needs of users with autism spectrum disorders. The current study observes the impact of the acoustic environment on repetitive speech and motor movement in children with autism. An observational study was conducted in four school classrooms to observe changes in behavior associated with changes in the decibel levels in the room. Forty-two children diagnosed with high-functioning autism between the ages of six and nine years old were observed in classroom settings. Variant decibel levels in the classrooms and variance in the frequency of repetitive behaviors were measured to determine the strength and direction of the correlations between the two. Results were analyzed using Noldus Observer XT software, and confirmed the hypothesized relationship. The finding that repetitive behavior is correlated with the acoustical condition of the environment should be considered in the design of classrooms for children with autism, for the benefit of user comfort and educational performance.
\end{abstract}

Keywords Acoustics, Repetitive Speech, Autism, Children

\section{Introduction}

As knowledge of autism spectrum disorders (ASD) develops alongside the Evidence-Based-Design (EBD) movement, the design of built environments that meet the unique needs of users with autism can become more precise. Autism is a neurodevelopmental disorder characterized by alterations in verbal and social skills, often accompanied by self-stimulatory behaviors and restrictive and repetitive motor movements and interests (American Psychiatric Association, 2013; Limbers, Heffer, \& Varni, 2009; Varni, et al., 2012). Many individuals with autism have atypical sensory processing mechanisms that cause them to have different sensitivities to the environment than other individuals (Tomchek \& Dunn, 2007). These environmental impacts on individuals with special needs are now being considered in architectural and interior design work (Mostafa, 2008). However, much more empirical research is needed for this work to continue.

Architect Jacques Black and clinical psychologist Cathy Lord both noted the lack of an evidence base for many of their design decisions in the construction of The Center for Autism and the Developing Brain (CADB) (DiNardo, 2015). Lord and Black identified noise control, careful use of color, and purposeful design as the central components of the design of the space. Specifically, the CADB building design has staggered wall studs, dual ceiling and walls, carpeting, and acoustic ceiling tiles to facilitate a calm acoustic environment (DiNardo, 2015). Scott (2009) also addresses unique design accommodations for students with autism, such as balancing security with independence, creating individual workspaces, and limiting detailing. While these design considerations for classrooms and schools as a whole are congruent with current hypotheses and theory about what constitutes best design practice for individuals with autism, there remains limited empirical evidence for these design choices. In order to answer how the physical environment can positively influence behavior, observational and experimental studies are needed.

\section{Restrictive and Repetitive Behaviors (RRBs)}

A common behavior for children with autism is obsessive self-stimulatory behavior, or repetitive actions that seemingly have no purpose (Wigham, et al., 2015). Repetitive behaviors are identified as behaviors that have no observable goal, but that are repetitiously done (Fenton \& Penney, 1985). Although the behaviors are observed in intellectually disabled individuals, individuals with psychosis, and individuals with autism, Fenton and Penney (1985) found the lighting in the built environment increased repetitive behavior in children with autism, but not repetitive behavior in children with intellectual disabilities. Engaging 
in repetitive behaviors in response to environmental stimuli is a characteristic assumed to be unique to individuals with autism.

Repetitive behaviors may be vocal or motor behaviors, including hand flapping and repeatedly uttering or echoing words or phrases (Lovaas, Varni, Koegel, \& Lorsch, 1977). Prior observational research has observed a number of stereotypies: arm flapping, banging and tapping, bizarre body movements, body bouncing, body rocking, body whirling and circling, crawling, darting and walking, finger flicking, foot tapping, head movements, jumping, leg swinging and rocking, oscillating, shoulder movements, slapping surrounds, and toe walking (Fenton \& Penney, 1985; Insel, 2013). Additionally, behaviors may include auto-manipulatives: hand to body, hand to ear, hand to eye, hand to face, hand to mouth, hand to nose, rubbing hands, and sniffing and sucking (Fenton \& Penney, 1985). This list is extensive, but may not be exhaustive. Individuals with autism may participate in an unlimited number of repetitive behaviors. The key to identifying a repetitive behavior is to distinguish when the behavior serves a function for the individual, and when the behavior appears to primarily serve the function of motor stimulation. The overarching term for these seemingly non-functional behaviors is the term "restrictive and repetitive behaviors" (RRB), and this term will be used throughout this article.

Theory and prior research suggests RRBs are linked to arousal level (Colman, Frankel, Edward, \& Freeman, 1976). Sensory under-responsiveness and sensory-over responsiveness are both observed to lead to increases in RRBs (Wigham, et al., 2015). Over responsiveness to external sensory stimuli predicts anxiety, while under- and over-responsiveness with anxiety and intolerance of uncertainty are found to reliably predict increases in repetitive motor behaviors and insistence on sameness (Wigham, et al., 2015). These findings suggest that the physiological and psychological effects of noise are pronounced for individuals with autism.

The acoustic environment is a primary issue for designing for individuals with autism, because of the high rate of live auditory hypersensitivity (hyperacusis) for this population (Baguley, 2013; Caldwell, 2006). Repetitive behaviors are a common feature of autism, and one of the most likely indicators of experiencing a sensory problem in the environment (Wigham, et al., 2015). The purpose of the present study is to understand the relationship between the acoustic environment and repetitive behaviors of children with autism in the classroom setting. Understanding the relationship between repetitive behaviors and environmental inputs will allow for enhanced guidelines and additional research on the best practices in design for individuals with autism.

\section{Physiological and Psychological Effects of the Built Environment}

Research has highly substantiated the impact psychological and physiological effects of ambient noise; annoying noises may result in stress, anger, disturbed concentration, difficulties in perception, and interference of typical functioning (Cheung, 2004; Finegold, Harris, \& Von Gierke, 1994; Ohrstrom, 1989). Noise may affect physiology by raising blood pressure, heart beat acceleration, changes in systolic rhythm, blood and endocrine changes, and muscle tension (Kanakri, 2012). For all individuals, continuous exposure to loud noises above the level of 85 decibels (dB) can lead to hearing loss (Atmaca, Pecker, \& Altin, 2005). While the impact of noise is idiosyncratic to individual users, on average, physiological responses are consistently observed (American Speech Language-Hearing Association, 2011; Anderson, Lindvall, Hursti, \& Carlbring, 2002). Many individuals with autism have problems with modulating sensory input (Wigham, et al., 2015). Negative acoustical conditions can alter concentration and physiological arousal in neurotypical individuals, and more so in individuals with altered sensitivity to the environment, and greater challenges with sensory integration. Experimental comparison study of lighting conditions found that repetitive behavior in children with autism was significantly increased by the presence of fluorescent lighting in the environment, while repetitive behaviors were not increased in children with other intellectual disabilities (Fenton \& Penney, 1985). The authors hypothesized that this occurred because of the physiological and psychological arousal associated with the flickering of fluorescent lighting (Colman, et al., 1976). These lighting studies and studies on the physiological effect of noise on people in general suggest research has begun to address the unique physiological and psychological experiences of individuals with autism, but much more research is needed to understand these environmental impacts, especially acoustics.

\section{The Acoustical Environment and Autism}

An international, 30-year study of 17,000 individuals with autism, found that $40 \%$ had some type of sound sensitivity (Rimland, \& Edelson, 1995). Hypersensitivity or hyperacusis is broadly defined as an unusual intolerance of the normal sounds in the environment, with loudness discomfort occurring at levels less than $70 \mathrm{~dB}$ (American Speech Language-Hearing Association, 2011).

At this time, the theoretical explanation for these acoustics difficulties is unclear. It is hypothesized that individuals with autism must expend greater cognitive effort to shift attention between stimuli, which may increase their difficulty in attending to necessary stimuli in an environment with a variety of ambient noises (Courchesne, 1989). Problematic behaviors may be connected to autonomic fear responses and emotional regulatory strategies (Stiegler, \& Davis, 2010). Anxiety, intolerance of uncertainty, or overwhelming 
physiological responses may be the cause of increased stimulatory behaviors, as a defense against boredom or a method of managing distress (Cheung, 2004; Wigham, et al., 2015).

Regardless of the mechanism of action, patterns of auditory filtering difficulties are associated with academic problems in children with autism, as children struggle to maintain engagement and process verbal instructions in a noisy environment (Ashburner, Ziviani, \& Rodger, 2008). Children who have difficulty processing verbal instructions and who are engaging in higher levels of RRBs are less likely to perform well academically (Ashburner, Ziviani, \& Rodger, 2008). Noise interference and physiological arousal deterring the understanding and sorting of auditory information is a significant concern, as children and teachers expend significant cognitive effort to focus and attend to learning in the classroom setting. Thus, acoustic design is an essential aspect of effective design for individuals with ASD (DiNardo, 2015).

Current general sensory guidelines for autism include suggestions such as sensory zoning, use of transition spaces between zones, adoption of escape spaces, and the use of visual clues to enhance way finding (Ashburner, Ziviani, \& Rodger, 2008). To this, further research can add information about the acoustical environment. Attention to the acoustical environment is expected to improve the well-being of individuals with autism as they engage in academic environments through minimizing negative environmental stimuli, thus decreasing their psychological and physiological distress, enhancing their ability to concentrate and decode auditory information, and improving their engagement and communication in the classroom. Presently, these hypotheses need to be tested via empirical data.

The purpose of the current research is to provide statistical information on the relationship between noise variance and RRBs of children with autism. Specifically the study compares frequency of repetitive behaviors and verbalizations under quiet versus loud conditions. This study hypothesized that a significant relationship between noise and repetitive behaviors would be found, with higher noise being positively correlated with repetitive behaviors in the classroom environment. The findings are used to draw conclusions about how interiors can be designed to enhance the acoustical experience of users with autism spectrum disorders.

\section{Methods}

\subsection{Setting}

Two schools for children with autism located in a southern state in the United States agreed to be in the study. Two classrooms from each school were identified as appropriate for the purposes of the study. In each school the interior environments of the classrooms were similar, but had essential differences in sources of external noise. These differences were important to the conditions of the study.

School 1: One classroom was located within two meters of the main playground area of the school. A heating, ventilation, and air-conditioning (HVAC) system connected to the room turned on an off every ten minutes. The highest $\mathrm{dB}$ level of noise was $94.7 \mathrm{~dB}$ and the lowest was $46.2 \mathrm{~dB}$. This classroom was coded as the loud. The other classroom in was located ten meters from the main playground area, and was not connected to the HVAC system. The highest $\mathrm{dB}$ level was $68.3 \mathrm{~dB}$ and the lowest was $40.3 \mathrm{~dB}$. This classroom was coded as quiet.

School 2: One classroom was located within four meters of the main playground area of the school. An HVAC system connected to the room turned on and off every ten minutes. The highest $\mathrm{dB}$ level of noise was $96.7 \mathrm{~dB}$ and the lowest was $50.5 \mathrm{~dB}$. This classroom was coded as loud. One classroom in this location was seven meters from the main playground area of the school, and was not connected to the HVAC system. The highest $\mathrm{dB}$ level of the noise was 69.7 $\mathrm{dB}$ and the lowest was $41.1 \mathrm{~dB}$. This classroom was coded as quiet.

\subsection{Participants}

Children with high functioning autism that met in these four classrooms were eligible to participate. Twenty high functioning children with autism (16 males) and (4 females) were included in this study from two classrooms in School 1. Twenty-two high functioning children with autism (21 males) and (1 female) were included in this study from two classrooms in School 2. Children's diagnoses were documented in their school file. In all cases diagnoses were provided by a pediatrician or a psychologist. In School 1, sixteen students had no intellectual impairment $(\mathrm{IQ}=85)$, three had mild intellectual impairment (IQ between 50 and 70) and one had severe intellectual impairment (IQ from 41 to 49). In School 2, fifteen had no intellectual impairment $(\mathrm{IQ}=85)$, five had mild intellectual impairment (IQ between 50 and 70), and one had severe intellectual impairment (IQ from 41 to 49). All subjects were enrolled in either $2^{\text {nd }}$ or $3^{\text {rd }}$ grade, ranged in age from 6-9 years, and had normal hearing.

\subsection{Ethics}

This study was approved by the Texas A\&M University Institutional Review Board - Human Subjects in Research. School administrators forwarded informed consent forms to parents to obtain permission for observation, recording sound levels, and videotaping children in the classrooms.

\subsection{Procedures}

Across seven weeks video data was collected. Observations ran from 8:30 am until 2:30 pm. Each week, approximately 20 hours of observations were recorded, in 
order to obtain 64 hours of data from each classroom. Observation occurred through video recording, dB recording, and researcher observation. The researcher trained a graduate student in the coding of the RRB and speech until adequate interrater reliability was achieved. The decibel levels and observations of repetitive motor movement and repetitive speech were then compared in the Noldus Observer XT program.

\section{Results}

\subsection{Relationship between $\mathrm{dB}$ and Repetitive Speech and Motor Movements}

An independent samples t-test was conducted to examine whether the loud classrooms had more instances of repetitive behavior and speech than the quiet classrooms. Levene's test was significant for both, therefore equal variances are not assumed and adjusted t-values are reported. The loud classrooms $(M=26.56, S D=27.34)$ had more instances of repetitive behavior than the quiet classrooms $(M=18.00, S D$ $=22.91), t(442.71)=3.72, p<.01$. The loud classroom $(M=$ 23.37, $S D=28.26)$ also had more instances of repetitive speech than the quiet classroom $(M=9.74, S D=17.44)$, $t(364.95)=6.30, p<.01$ (see Table 1$)$.

Pearson correlation coefficients were also calculated to examine the relationship between $\mathrm{dB}$ and repetitive behavior and speech. There was a significant positive correlation between repetitive speech and $\mathrm{dB}, r(488)=.311, p<.01$, indicating as $\mathrm{dB}$ levels increase, repetitive speech increases. There was also a significant positive correlation between repetitive behavior and $\mathrm{dB}, r(488)=.302, p<.01$, indicating as $\mathrm{dB}$ levels increase, repetitive behaviors increase. Lastly, there was a significant positive correlation between repetitive speech and repetitive behaviors, $r(488)=.207, p$ $<.01$, indicating as repetitive speech increases, repetitive behaviors increase.

Data on repetitive speech and repetitive behavior were then combined. An independent samples t-test was conducted to analyze whether loud classrooms had more instances of repetitive behavior and speech than the quiet classrooms. Levene's test was significant, therefore equal variances are not assumed and adjusted t-values are reported. The loud classrooms $(M=49.93, S D=2.81)$ had more instances of repetitive behavior and speech than the quiet classrooms $(M=27.75, S D=1.93), t(410.17)=6.507, p$ $<.01$ (see Table 1). Pearson correlation coefficient was then calculated to determine the relationship between $\mathrm{dB}$ and repetitive behaviors and speech. There was a significant positive correlation between $\mathrm{dB}$ and repetitive behavior and speech, $r(488)=3.94, p<.01$, indicating as $\mathrm{dB}$ levels increase, instances of repetitive behavior and speech increase (see Table 2).

The average number of occurrences per 15-minute interval for each target behavior was calculated from frequency distribution data. The 41-55 dB range represents what is considered a quiet or normal classroom. During periods when the sound level in the classrooms was quiet, the average occurrence of repetitive motor movement was $\mathrm{M}=$ 10.36 , and of repetitive speech was $\mathrm{M}=8.37$. The $55-70 \mathrm{~dB}$ range represents a loud classroom. During periods when the sound level in the classrooms was loud the average occurrence for behavior for repetitive motor movement was $M=24.12$, and of repetitive speech was $M=12.32$. In this range, on average, repetitive motor movement occurred 13.76 more times and repetitive speech occurred 3.95 more times than they did during quiet periods of time. The $>70 \mathrm{~dB}$ range has potential to result in hearing loss. For this range, repetitive speech occurred on average $\mathrm{M}=29.40$, per 15-minute interval. Repetitive motor movement occurred on average $\mathrm{M}=8.61$, per 15-minute interval. In comparison to the loud $\mathrm{dB}$ level, on average, repetitive speech occurred 17.08 more times and repetitive motor movement occurred 15.51 less times (see Table 3).

Table 1. Behavior Means and Standard Deviations with t-test information for $\mathrm{dB}$ Levels $(\mathrm{N}=488)$

\begin{tabular}{|c|c|c|c|}
\hline Classroom & Loud & Quiet & t-value $(d f)$ \\
\hline & Mean $(S D)$ & Mean $(S D)$ & \\
\hline $\begin{array}{c}\text { Repetitive speech and } \\
\text { behaviors }\end{array}$ & $49.93(2.81)$ & $27.75(1.93)$ & $6.507 * * *$ \\
\hline
\end{tabular}

Note. $* p<.05$, two-tailed. $* * p<.01$, two-tailed. $* * * p<.001$, two-tailed

Table 2. Correlation between $\mathrm{dB}$ Levels and Repetitive Speech and Behavior

\begin{tabular}{|c|c|}
\hline & Repetitive speech and behavior \\
\hline $\mathrm{dB}$ & $3.94 * * *$ \\
\hline
\end{tabular}

Note. $* p<.05$, two-tailed. $* * p<.01$, two-tailed. $* * * p<.001$, two-tailed

Table 3. Average Occurrence of Target Behaviors per 15 Minutes

\begin{tabular}{|c|c|c|c|}
\hline Noise level & $\begin{array}{c}41-55 \mathrm{~dB}(\mathrm{~N}= \\
130)\end{array}$ & $\begin{array}{c}55-70 \mathrm{~dB}(\mathrm{~N}= \\
221)\end{array}$ & $\begin{array}{c}>70 \mathrm{~dB}(\mathrm{~N}= \\
138)\end{array}$ \\
\hline Repetitive Speech & 8.37 & 12.32 & 29.40 \\
\hline $\begin{array}{c}\text { Repetitive Motor } \\
\text { Movement }\end{array}$ & 10.36 & 24.12 & 8.61 \\
\hline
\end{tabular}

\section{Discussion}

Congruent with prior findings, the present study shows that a relationship between noise levels and repetitive behaviors is reliably present (Colman, Frankel, Edward, \& Freeman, 1976; Wigham, et al., 2015). As expected, quiet classrooms are associated with less frequent repetitive speech and behaviors, while loud classrooms are associated with greater frequency of repetitive speech and behaviors. This study builds on previous studies that suggest there is a relationship between the acoustic environmental inputs and RRBs, and provides additional support for the argument that environmental factors, such as acoustics and lighting, have an impact on the behavior of individuals with autism. The hypothesis that increased noise levels impacts repetitive 
behavior is particularly supported by the increased frequency of repetitive speech and motor movements in the Loud Range (55-70 dB). At the Potentially Damaging range ( $>70$ $\mathrm{dB}$ ) repetitious behavior decreases, while repetitious verbal behavior increases. Future research might consider whether repetitive verbal behavior is a sign of more significant distress, or a situation in which verbal complaints seem more justified.

The study has limitations due to the correlational nature of the findings at this time. Testing this relationship through controlled studies to show causality would strengthen the argument. Further, as previously mentioned, the acoustic environment may only account for part of the physiological disruption and low-grade annoyance that is believed to be caused by extraneous noise. Other impacts, such as the type and brightness of the lights, have also been found to impact repetitive behaviors. Alternatively, internal triggers for repetitive speech and motor behaviors could be explored in addition to the environmental impacts. Interpersonal factors, such as the teacher-student and student-student relationship, should also be considered. Thus, a number of variables could be used to explain increased counts of repetitive speech and behavior, and further consideration for how these variables may moderate the relationship between the acoustic environment and repetitive speech and motor behaviors.

\section{Conclusions}

By understanding the mechanisms of autism spectrum disorders and consequent needs of the user with autism, the environment may be designed to create an environment conducive to skill development and learning for individuals with autism (Mostafa, 2008). In conjunction with other important environmental considerations, the acoustic environment is an important aspect of consideration when designing the built environment to be conducive to the comfort of individuals with ASD. The current findings support the importance of well-designed acoustic environments for decreasing distress increasing positive behavior. In particular, educational settings should consider these findings a priority to enhance children's abilities to function effectively in the learning environment. Future research should consider experimental methods to further clarify the causal nature of the relationship, as well as the underlying mechanisms associated with this phenomenon.

\section{Conflict of Interest}

The author has declared no conflict of interest, and this research did not receive any funding.

\section{REFERENCES}

[1] American Psychiatric Association. (2013). Diagnostic and statistical manual of mental disorders ( $5^{\text {th }}$ ed.). Arlington, VA: American Psychiatric Publishing.

[2] American Speech Language-Hearing Association (2011) Hyperacusis, Audiological Information Series, 1-2.

[3] Anderson, G, Lindvall, N, Hursti, T, and Carlbring, P (2002) Hypersensitivity to sound (hyperacusis): A prevalence study conducted via the internet and post, International Journal of Audiology, 41(8), 545-554.

[4] Ashburner, J, Ziviani, J, and Rodger, S (2008) Sensory processing and classroom emotional, behavioral, and educational outcomes in children with autism spectrum disorder, American Journal of Occupational Therapy, 62, 564-573.

[5] Ashtead Technology (1999) QUET Manual, Retrieved from http://ashtead-technology.com.

[6] Atmaca, E, Pecker, I, and Altin, A (2005) Industrial noise and its effects on humans, Polish Journal of Environmental Studies, 14(6), 721-726.

[7] Baguley, D (2013) Definitions, epidemiology and possible mechanisms of hyperacusis, Audiology Matters, 21(6), 70-71.

[8] Caldwell, P (2006) Finding you finding me, London: Jessica Kingsleu Publishers.

[9] Cheung, C (2004) Organizational influence on working people's occupational noise protection in Hong Kong, Journal of Safety Research, 35(4), 465-475.

[10] Colman, R, Frankel, F, Edward, R, and Freeman, B (1976) The effects of fluorescent and incandescent illumination upon repetitive behaviors in autistic children, Journal of Autism and Childhood Schizophrenia, 6(2), 157-162.

[11] Courchesne, E (1989) Implications of recent neurobiological finding in autism, Washington, DC: Autism Society of America.

[12] DiNardo, A (2015, November) 3 lessons in designing for autism, Healthcare Design, retrieved fromhttp://www.health caredesignmagazine.com/article/3-lessons-designing-autism.

[13] Fenton, D, and Penney, R, (1985) The effects of fluorescent and incandescent lighting on the repetitive behaviors of autistic and intellectually handicapped children, Australia and New Zealand Journal of Developmental Disabilities, 11(3), 137-141.

[14] Finegold, L, Harris, C, and Von Gierke, H (1994) Community annoyance and sleep disturbance: Updated criteria for assessing impacts of general transportation noise on people, Noise Control Engineering Journal, 42(1), 25-30.

[15] Insel, $\mathrm{T}$ (2013) Transforming diagnosis, retrieved from http://www.nimh.nih.gov.

[16] Kanakri, S (2012) The effect of noise on children with autism behavior, EDRA Proceeding.

[17] Limbers, C, Heffer, R, and Varni, J (2009) Health-related quality of life and cognitive functioning from the perspective of parents of school-aged children with Asperger's syndrome utilizing the PedsQL ${ }^{\mathrm{TM}}$, Journal of Autism and Developmental Disorders, 39, 1529-1541. 
[18] Lovaas, O, Varni, J, Koegel, R, and Lorsch, N (1977). Some observations on the non-extinguish ability of children's speech, Child Development, 48, 1121-1127.

[19] Mostafa, M (2008) An architecture for autism: Concepts of design intervention for the autistic user, International Journal of Architectural Research, 2, 189-201.

[20] Ohrstrom, E (1989) Sleep disturbance, psychosocial and medical symptoms: A pilot survey among persons exposed to high levels of road traffic noise, Journal of Sound and Vibrations, 133(1), 117-128.

[21] Rimland, B, and Edelson, S (1995) Brief report: A pilot study of auditory integration training in autism, Journal of Autism and Developmental Disorders, 25, 61-70.

[22] Scott, I. (2009). Designing learning environments for children on the autism spectrum.Good Autism Practice, 10(1), 36-51.

[23] Stiegler, L, and Davis, R (2010) Understanding sound sensitivity in individuals with autism spectrum disorders,
Focus on Autism and Other Developmental Disabilities, 25(2), 67-75.

[24] Tomchek, S. D., \& Dunn, W. (2007). Sensory processing in children with and without autism: a comparative study using the short sensory profile. American Journal of occupational therapy, 61(2), 190-200.

[25] Varni, J, Handen, B, Corey-Lisle, P, Guo, Z, Manos, G, Ammerman, D, ... Mankoski, R (2012) Effect of Aripiprazole 2 to $15 \mathrm{mg} / \mathrm{d}$ on health-related quality of life in the treatment of irritability associated with Autistic Disorder in children: A post hoc analysis of two controlled trials, Clinical Therapeutics, 34, 980-992.

[26] Wigham, S, Rodgers, J, South, M, McConachie, H, and Freeston, M (2015) The interplay between sensory processing abnormalities, intolerance of uncertainty, anxiety and restricted and repetitive behaviors in autism spectrum disorder, Journal of Autism and Developmental Disorders, 45, 943-952. 